\title{
Jejunal Fistula Complicating Ovarian Serous Carcinoma: Case Report of a Rare Phenomenon and Review of the Literature
}

\author{
Isin UREYEN1, Tayfun TOPTAS', Sezin ATES TATAR², Gulsum EKIN², Faruk GULEC³, Aysel UYSAL ${ }^{2}$ \\ Antalya, Turkey
}

\begin{abstract}
Invasion of the wall of the digestive system by ovarian cancer cells isn't so rare. On the other hand, fistula formation between the tumor and digestive system is an uncommon status. We described a patient with ovarian serous carcinoma that was fistulized into jejunum and formed a region composed of stool and tumor surrounded and limited by small intestines recognized during surgery. This diagnosis should be kept in mind while preparing a patient for ovarian cancer surgery if the patient has acute abdomen or abdominal pain incompatible with the extent of the tumor.
\end{abstract}

Keywords: Ovarian cancer, Fistula, Surgery

Gynecol Obstet Reprod Med 2021;27:(2):184-186

\section{Introduction}

Ovarian cancer is the most common gynecological cancer causing mortality in women (1). Patients with ovarian cancer come with abdominal pain, distention, bloating or weight loss at advanced stages. However, at early stages patients are usually asymptomatic and the tumors are diagnosed incidentally (2). Invasion of the wall of the digestive system by tumor cells isn't so rare. On the other hand, fistula formation between the tumor and digestive system is an uncommon status.

In the present case, we described a patient with ovarian serous carcinoma that was fistulized into jejunum and formed

\footnotetext{
${ }^{1}$ University of Health Sciences, Antalya Teaching and Research Hospital, Department of Gynecological Oncology, 2Department of Gynecology and Obstetrics, ${ }^{3}$ Department of Pathology, Antalya, Turkey Address of Correspondence: Isin Ureyen

University of Health Sciences, Antalya Teaching and Research Hospital, Department of Gynecology and Obstetrics, 07025, Muratpasa, Antalya, Turkey isin.ureyen@gmail.com
}

Submitted for Publication: 13.07.2018 Revised for Publication: 26.08.2018 Accepted for Publication: 10.01.2019 Online Published: 02.08.2021

ORCID IDs of the authors: TT: 0000-0002-6706-6915 IU:0000-0002-3491-4682 SAT:0000-0003-4516-3076 GE: 0000-0003-2618-7603 AY: 0000-0001-6488-8385

\begin{tabular}{|c|c}
\hline \begin{tabular}{c} 
Quick Response Code: \\
\cline { 2 - 2 }
\end{tabular} & Access this article online \\
\cline { 2 - 2 } & $\begin{array}{l}\text { Website: www.gorm.com.tr } \\
\text { e- mail: info@gorm.com.tr }\end{array}$ \\
\cline { 2 - 2 } & DOI:10.21613/GORM.2018.816 \\
\hline
\end{tabular}

How to cite this article: Ureyen I. Toptas T. Ates Tatar S. Ekin G. Gulec F. Uysal A. Jejunal Fistula Complicating Ovarian Serous Carcinoma: Case Report of a Rare Phenomenon and Review of the Literature. Gynecol Obstet Reprod Med 2021;27(2):184-186. a region composed of stool and tumor surrounded and limited by small intestines recognized during surgery.

\section{Case Report}

A 72 years old multiparous woman was admitted to emergency department with abdominal pain. Extensive ascites was observed and she was hospitalized. Detailed examination was performed. Her computed tomography (CT) scan revealed thickening of the peritoneal surfaces, bilateral adnexal masses and extensive ascites. The mass in the left side was considered to fistulize into intestine. Ca-125 was $1002 \mathrm{U} / \mathrm{mL}, \mathrm{Ca}-15.3$ was $56 \mathrm{U} / \mathrm{mL}$ and CEA and $\mathrm{Ca}-19.9$ were within the normal limits. WBC was $9700103 / \mathrm{mm} 3$ and sedimentation was 140 $\mathrm{mm} / \mathrm{s}$. Her mammography was normal. Upper endoscopy revealed no pathology. Her abdominal pain declined. She was transferred to the service of gynecological oncology, since ovarian pathology was the primary diagnosis. Total hysterectomy, bilateral salphingo-oopherectomy, total omentectomy, pelvic peritonectomy, appendectomy, jejunal resection, low anterior resection, primary jejunal anastomosis, primary colorectal anastomosis and loop ileostomy opening were performed. In the operation, there was only $100 \mathrm{cc}$ inflamed ascites, all the small intestines were adhered to each other and to the large intestine. The uterus, 6-7 cm tumoral masses in the both ovaries, sigmoid colon and small intestines formed a conglomerate mass in the pelvis. All peritoneal surfaces seemed inflamed. Omentum seemed inflamed and thickened. During the dissection of small intestine from the mass, a loop of jejunum was detected to fistulize in to the left ovarian tumoral mass and a hidden zone composed of left ovarian tumoral mass and stool behind the left side of the uterus with strong odor that was limited by small intestine and sigmoid colon was observed. There was no stool in the abdomen except this zone. After dissecting the fistulized loop of jejunum, the con- 
glomerate mass was removed en-bloc with some part of sigmoid colon and rectum (Figure 1), it was sent for frozen section. Frozen section revealed serous malignant tumor. The loop of jejunum with the fistula tract (Figure 2) was removed and primary jejunal anastomosis was performed. Primary colo-rectal anastomosis was done. A loop ileostomy $30 \mathrm{~cm}$ proximal to the ileocecal valve was created. Since the primary jejunal anastomosis was in the proximal jejunum, the ostomy couldn't be created proximal to it.

Lymph node dissection couldn't be performed because of the prolonged surgery time (510 minutes). Maximal debulking was achieved. She was observed in the intensive care unit for 1 day and then she was transferred to the service of gynecological oncology. Bile content was observed in the abdominal drain in the $7^{\text {th }}$ postoperative day. Oral intake was stopped and total parenteral nutrition was given during this time period. After 3 days, her drain didn't bring anything and at the $14^{\text {th }}$ postoperative day oral intake was started again. Beside these, any other postoperative complication didn't occur. Her pathology report showed high grade serous carcinoma in the both ovaries, omentum, resected small intestine, myometrium,

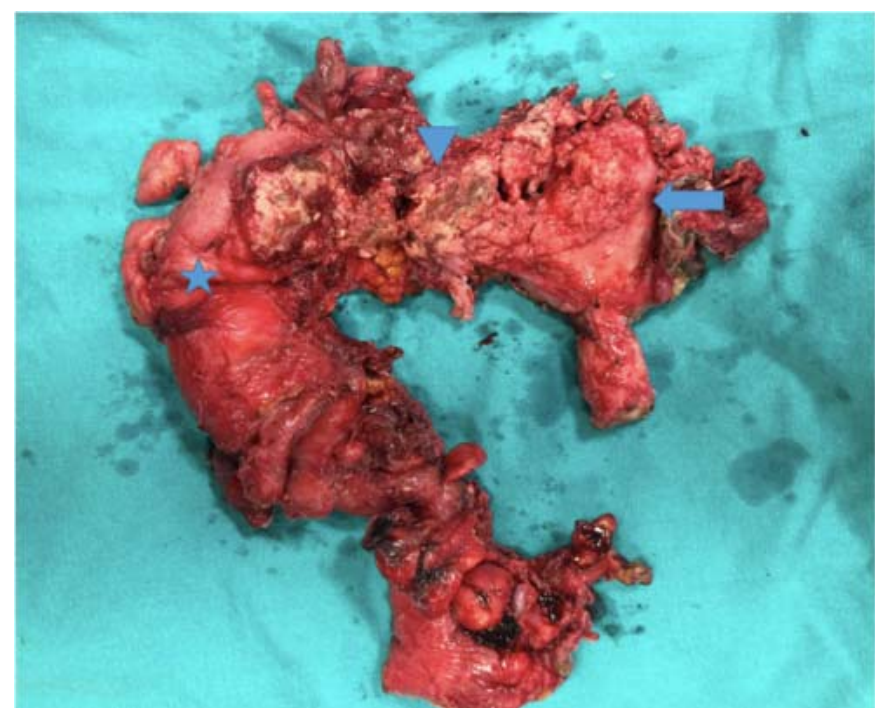

Figure 1: Part of the left tumoral mass (arrowhead) invading myometrium (arrow) and sigmoid colon (star) removed en-bloc. pelvic peritoneum. She was transferred to the service of medical oncology in the $30^{\text {th }}$ postoperative day for chemotherapy after completing 2 weeks of ertapenem and 1 week of tigecycline antibiotherapy. She completed 6 cycles of chemotherapy without trouble. Following the last cycle of chemotherapy, Ca125 level was $21 \mathrm{U} / \mathrm{mL}$ and PET-CT revealed no pathological finding. Informed consent was taken from the patient for sharing the data.

\section{Discussion}

We presented a case of ovarian cancer presenting with abdominal pain due to fistulization of the tumor into the small intestine. In the progression of ovarian cancer in the abdomen, invasion of adjacent organs is commonly observed in advanced stages of the disease. However, spontaneous fistulization of ovarian cancer into digestive tract with a fistula tract is a different and rare phenomenon. On the other hand, fistulization into digestive tract could be iatrogenic and observed more commonly due to advanced cytoreductive surgery or during taking chemotherapy especially anti-VEGF therapy (3).

Malignant epithelial ovarian cancer fistulizing into digestive tract has been reported in only 4 cases before this case (Table I). There were 2 patients with serous carcinoma, 2 patients with clear cell and 1 patient with mucinous cell carci-

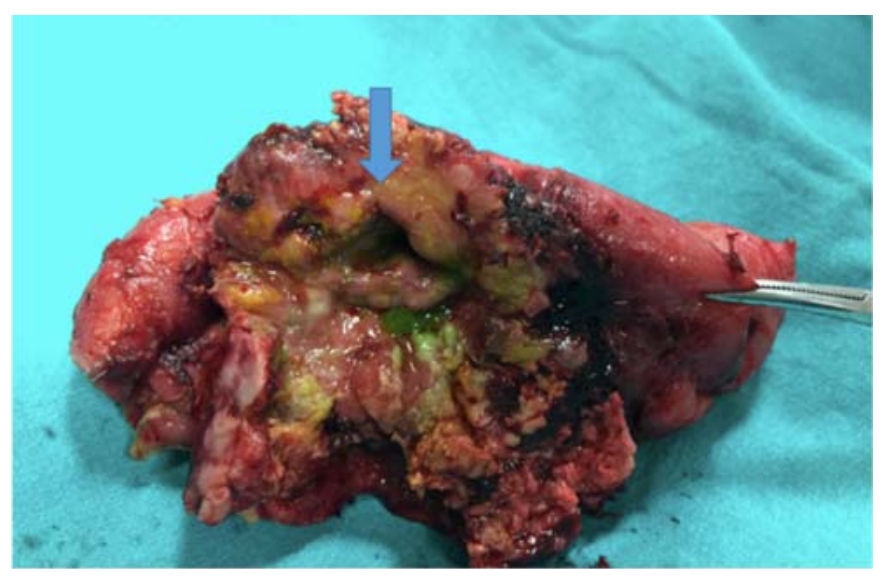

Figure 2: Part of jejunum with the tumor forming the fistula tract (arrow)

Table I: Clinico-pathological characteristics of patients with epithelial ovarian cancer and fistula formation into digestive system

\begin{tabular}{|c|c|c|c|c|c|c|}
\hline Patient & $\begin{array}{c}\text { Age } \\
\text { (Years) }\end{array}$ & Symptoms & $\begin{array}{l}\text { Pathology of Malign } \\
\text { Epithelial Tumor }\end{array}$ & \begin{tabular}{|c|} 
Tumor \\
size $(\mathrm{cm})$
\end{tabular} & $\begin{array}{c}\text { Part of the Digestive } \\
\text { Tract }\end{array}$ & Reference \\
\hline 1 & 62 & $\begin{array}{l}\text { Abdominal pain, } \\
\text { weight loss }\end{array}$ & Serous & 10 & Recto-sigmoid colon & Honda et al. $(1990)^{4}$ \\
\hline 2 & 57 & $\begin{array}{l}\text { Abdominal pain, } \\
\text { distention, shock }\end{array}$ & Mucinous & - & Rectum & Skipper et al. $(1995)^{6}$ \\
\hline 3 & 61 & $\begin{array}{l}\text { Abdominal pain, } \\
\text { weight loss }\end{array}$ & Clear & $10 \times 14$ & Sigmoid colon, ileum & Kim et al. $(1999)^{5}$ \\
\hline 4 & 61 & $\begin{array}{l}\text { Bloody bowel discharge, } \\
\text { abdominal distention }\end{array}$ & Clear & 26 & Sigmoid colon & Yahagi et al. $(2011)^{1}$ \\
\hline 5 & 72 & Abdominal pain, distention & Serous & 8-bilateral & Jejunum & Present case \\
\hline
\end{tabular}


noma including the present case (1,4-6). Among these 5 patients, the median age of the patients was 61 (range, 57-72). Abdominal pain and distention was the most common symptoms. Small intestine is a less frequent place for fistulization, only in one case fistulization into ileum was reported. Jejenum hasn't been reported before as a place of fistulization. In the present case, in the preoperative $\mathrm{CT}$, fistulization of tumor into intestines was suspected. Similarly, in 4 previous cases, fistula formation was diagnosed preoperatively by barium enema or CT. Tumoral invasion together with chronic inflammation was considered to be the cause of fistula formation in these cases (1).

Mature cystic teratoma is the most commonly reported ovarian tumor to fistulize into adjacent organs in the literature if all types ovarian tumors are considered. Since the first case report showing a mature ovarian teratoma that was fistulized into bladder was presented in 1938 by Robinson et al. above 30 cases of ovarian teratoma have been reported $(7,8)$. The most common organs of fistulizaton was colon, bladder, small intestine. More rarely cases presenting fistulization into uterus, vagina and abdominal wall were also presented (9-10). Malignant transformation especially, squamous cell carcinoma normally occurs less than $2 \%$ of the cases with ovarian teratoma (11). However, in the review by Kizaki et al, squamous malignant transformation was observed in $4(23,5 \%)$ of 17 cases with ovarian teratoma fistulized into neighboring organs (8). On the other hand, still most of the fistula cases were due to benign teratomas. This suggested that a different mechanism of fistulization other than tumoral invasion should be considered for ovarian teratomas. Chemical irritation of the contents of teratomas leading to granulamatous reactions and adhesions between adjacent organs has been blamed for fistulization of benign teratomas (12).

In the cases with epithelial ovarian cancer, fistulization into digestive tract is a are phenomenon. However, when present, this complication increases the risk of morbidity by increasing the duration of the procedure and by increasing the risk of postoperative complications. This diagnosis should be kept in mind while preparing a patient for ovarian cancer surgery if the patient has acute abdomen or abdominal pain incompatible with the extent of the tumor.

The authors declared that there is no conflict of interest. Acknowledgement: None

Funding: None

\section{References}

1. Yahagi N, Kobayashi Y, Ohara T, Suzuki N, Kiguchi K.
Ishizuka B, Ovarian carcinoma complicated by sigmoid colon fistula formation: A case report and review of the literature, J Obstet Gynaecol Res. 2011;37(3):250-3. doi: 10.1111/j.1447-0756.2010.01341.

2. Doubeni CA, Doubeni AR, Myers AE, Diagnosis and Management of Ovarian Cancer, Am Fam Physician. 2016;93(11):937-44. PMID: 27281838.

3. Sfakianos GP, Numnum TM, Halverson CB, Panjeti D, Kendrick JE $4^{\text {th }}$, Straughn JM Jr. The risk of gastrointestinal perforation and/or fistula in patients with recurrent ovarian cancer receiving bevacizumab compared to standard chemotherapy: a retrospective cohort study. Gynecol Oncol. 2009;114(3):424-6. doi:10.1016/j.ygyno.2009.05. 031.

4. Honda H, Lu CH, Barloon TJ, Hashimoto K. Sigmoid colon fistula complicating ovarian cystadenocarcinoma: A rare finding. Gastrointest Radiol. 1990;15:78-81. doi: 10. 1007/BF01888743.

5. Kim SJ, Kimoto Y, Nakamura H. et al. Ovarian carcinoma with fistula formation to the sigmoid colon and ileum: Report of a case. Surg Today. 1999;29:449-52. doi: 10. 1007/BF02483039.

6. Skipper D, Moran B, Dormandy JA, Heald RJ. Two cases of colo-ovarian cyst fistula. Int J Colorectal Dis. 1995;10: 70-2. doi: 10.1007/BF00341198.

7. Robinson RH. Ovarian Teratoma, invading the bladder. Proc R Soc Med.1938;31:1076-7. PMID: 19991593.

8. Kizaki Y, Nagai T, Ohara K, Gomi Y, Akahori T, Ono Y, et al. Ovarian mature cystic teratoma with fistula formation into the rectum: a case report. Springerplus. 2016;5 (1):1700. doi: 10.1186/s40064-016-3426-4.

9. Atalay MA, Orhan A, Oz Atalay F, Saydam I, Cetinkaya Demir B. Cutaneous Fistulization of an Ovarian Mature Cystic Teratoma: An Unusual Occurrence. Gynecol Obstet Invest. 2015;80(1):64-6. doi: 10.1159/000431225.

10. Bouzid F, Pasquier D, Squercioni A, Henry YS, Racinet C. Benign teratoma of the ovary with fistula to the uterus, J Gynecol Obstet Biol Reprod. 1993;22(3):259-60. PMID: 8345149 .

11. KW Min, SJ Lee, HY Jung, HS Han, SY Lee, MK Seong, et al. Squamous Cell Carcinoma Arising in a Mature Cystic Teratoma Exposed through a Colo-ovarian Fistula. J Obstet Gynaecol. 2015;35(7):763-4. doi: 10.3109/ 01443615.2015.1007339.

12. von-Walter AR, Nelken RS. Benign cystic ovarian teratoma with a fistula into the small and large bowel. Obstet Gynecol. 2012;119(2):434-6. doi:10.1097/AOG.0b013 e3182319185. 